Sharif University of Technology

Scientia Iranica

Transactions D: Computer Science \& Engineering and Electrical Engineering

http://scientiairanica.sharif.edu

\title{
Detection of the stator inter-turn fault using the energy feature of the wavelet coefficients obtained through continuous wavelet transform
}

\author{
S.M. Hossein and M. Abedi* \\ Electrical Engineering Department, Shahid Beheshti University, Tehran, P.O. Box 19839-69411, Iran.
}

Received 16 August 2020; received in revised form 28 May 2021; accepted 2 August 2021

\author{
KEYWORDS \\ BLDC motor; \\ Stator inter-turn \\ fault; \\ CWT; \\ Fault detection; \\ ADAMS software.
}

\begin{abstract}
This research aims to investigate the application of a fault detection method to the stator part of the Brush-Less DC (BLDC) motor. Indeed, it is important to ensure that the motor is operating in a healthy mode and in any other case, it is of great importance to detect the fault as soon as possible to prevent further ruin of the major system. To this end, a sub-branch method of wavelet transform analysis, called Continuous Wavelet Transform (CWT), was utilized to observe the short-circuit fault in the stator coils. In addition, a novel simulator of the BLDC motor was developed by forming an interconnection between ADAMS and MATLAB, which incorporated different electrical and mechanical components. As a result, a close-to-reality model of the BLDC motor was achieved that ensured more accurate evaluation of the proposed method. An energy-type feature was then suggested to characterize fault occurrence. The amount of the normalized energy was obtained for one of the wavelet coefficient signals caused by the CWT and the energy was compared with a predefined threshold amount of energy for that signal to facilitate the detection of the flawed performance of the stator. The proposed method can be further validated through different simulations.

(C) 2023 Sharif University of Technology. All rights reserved.
\end{abstract}

\section{Introduction}

Due to their reliability and efficiency, Brush-Less DC (BLDC) motors are acknowledged to be excellent candidates to be applied in different application fields including aerospace systems, chemical industry, and electric vehicles, to mention a few [1-3]. The motor that functions in an unhealthy mode will undoubtedly cause serious problems and issues that in turn decrease the efficiency, safety, and reliability of the system.

\footnotetext{
*. Corresponding author. Tel.: +98 21 73932628; Fax: +982122431919

E-mail addresses: saba.mhosseini@gmail.com (S.M. Hosseini); mo_abedi@sbu.ac.ir (M. Abedi)
}

Accordingly, prompt diagnosis of any defect within the system is essential that has a major impact on the continuity of the equipment operation in a reliable and safe mode.

To date, several fault diagnosis methods have been developed; however, they failed to detect the internal faulty parts of the actuator. These methods were established mainly based on control system modeling or data sets [4-6]. Given this, a different branch of works called the signal-based methods was developed for module condition monitoring with the main focus on measuring a crucial signal. Signalbased approaches work in time [7], frequency [8], and time-frequency [9] domains. Fault detection in a timefrequency domain, as opposed to time-based ones, is one of the approved methods where the measured signal must undergo noticeable changes during its evolution 
through time. Contrarily, frequency-based algorithms may only be applied to either stationary or periodic non-stationary signals. Since the loading condition on the BLDC motor might differ depending on the presence of no load or changeable load, the system signals can be considered dynamic containing a transient part in general. Therefore, the frequency spectrum might alter with respect to time and hence, each time or frequency algorithm cannot be very effective. Recently, time-frequency approaches have been widely applied to electrical machines as a practical means of fault detection, and several research papers have been published in this field. For instance, Da Costa et al. [10] studied the applicability of two methods, i.e., Fast Fourier Transform (FFT) and wavelet, to detect the broken bars in induction motors. The obtained results in this research point out the slight superiority of Wavelet Transform (WT) method to the FFT in terms of fault detection purposes. Moravej et al. [11] presented an algorithm to identify a high impedance fault using the dual-tree complex WT. They remarked that the approach was highly dependable and secure. Abed et al. proposed a novel approach using Discrete Wavelet Transform (DWT) and a recurrent neural network [12].

Defective stator windings in electrical motors constitute a large percentage of the usual faults. The stator fault may start from unknown short-circuited turns in a coil and then, undergo a transformation into the phase-to-phase or even phase-to-ground short circuits, thus causing tremendous and irreparable damage followed by a forced system shutdown in each of two cases.

For this reason, obtaining accurate information about any error in the stator windings gains significance, hence being extensively studied. Take the study conducted by Elbouchikhi et al. for example [13]. The current study aimed to propose a new approach to detect the stator faults in the inverterfed induction motor under closed-loop control. Afrandideh et al. developed a flux-based approach [14] for online detection of the stator defects in synchronous generators. Hu et al. [15] offered an inter-turn shortcircuit fault diagnosis technique for permanent magnet machines based on the current residual. Sá et al. [16] investigated a scheme to detect the stator faults in the first moments using a classifier module based on a multilayer perceptron neural network and analyzing the stator electrical current patterns. Shifat and Hur [17] suggested another approach to diagnose the insulation break in the stator winding by combining vibration and current signals collected from sensors. Akhil Vinayak et al. invented a new real-time incipient Stator Inter-Turn Fault (SITF) diagnosis algorithm in [18] by conducting DWT analysis on the stator current in the inverter-fed induction machines.

In general, the systems that operate in a station- ary mode can be analyzed using the classic Fourier Transform (FT) techniques. However, FT analysis cannot be proper in the case of a non-stationary system or in a transient state. These systems usually employ time-frequency methods such as short-time Fourier transform or time-scale algorithms like WT.

The present study developed a fault detection algorithm based on Continuous Wavelet Transform (CWT) tool to detect the SITF. To this end, the Wavelet Coefficients (WC) signals were extracted from the stator phase current signal. Since the position and scale parameters, respectively, related to time and frequency contribute to obtaining WCs, the method works in a time-frequency domain that enjoys several advantages, as previously mentioned. In [19], diagnosis of fault in electric motors was studied using wavelet methods and diagnosing the short-circuit faults in the stator winding using CWT. Despite these studies and some other nearly related works such as the study of Zandi and Poshtan [20], this study presented an energy-based approach towards the signals obtained from CWT. Moreover, a more accurate model of the BLDC motor was extracted using MATLAB and ADAMS. In this regard, followed by determination of the specific frequencies associated with the SITF, the energy amounts of the required WCs were obtained and analyzed. As observed, in case of fault occurrence, there would be a higher amount of cumulative energy in one or more of the WC signals, thus leading to the faulty situation determination. Calculation of the energies of the WC signals highlights a more distinct feature for fault detection rather than the criteria used in other research studies such as Frosini et al. [21], where the shape and form of the WC signals were considered the basis for the fault detection. The energy amount of a signal renders a numerical criterion that can be later compared between different fault intensities which is more scientific than the mere shape of the signal itself. Therefore, the signal under inspection to detect fault occurrence can be constantly and rapidly checked for any faults initiating in the system.

Many researchers have employed the standard BLDC motor model as a mathematical dynamic equation $[3,22,23]$. Although this model tries to incorporate as many aspects of the actual motor as possible, some elements such as static and dynamic imbalances of the rotor have not yet been included in this model. Here, the proposed algorithm is applied to the stator phase current obtained from an enhanced BLDC motor model simulated in MATLAB and ADAMS. Although our proposed mathematical model already incorporated the electrical and mechanical parts of the motor and their relations, there might still be some mismatches between the MATLAB model and the real BLDC motor. For this reason, a novel modeling methodology was developed using MATLAB and ADAMS software. Of 
note, ADAMS software plays a vital role in providing a closer-to-the-reality model of the motor. In the case of using only MATLAB to design the model, one cannot closely model the mechanical parts and affiliated imbalances as in the case of using ADAMS software. To be more precise, the rotor part is designed in the ADAMS software and then, the ADAMS block is related to the stator and driver modules that were already developed in MATLAB. Finally, this more detailed model provides a more accurate evaluation of the proposed algorithm.

The paper contributions are elaborated in the following. First, fault occurrence is determined at not only the equipment level but also the internal elements level. In this respect, this method is superior to the model-level approaches [4]. Second, given that the method is not data-oriented, its performance does not rely on the existence of a rich dataset like the research done by Skowron et al. [24] and Maraaba et al. [25]. Third, both time and frequency features of the fault can be obtained and since this method operates in the frequency domain method as opposed to [8], it can be implemented on the transient part of the signal as well as on its steady-state duration. Fourth, a novel characteristic can be developed to quickly decide on the fault occurrence and its severity. Use of this feature makes it possible to precisely determine the intensity of the fault by a numerical value, despite the studies conducted by Zandi and Poshtan [20], Frosini et al. [21], and Rao et al. [26]. Finally, the ADAMS simulator developed here is a tool that takes the classic MATLAB motor model to a higher accuracy level, as opposed to the results obtained by Rao et al. [26] and Salehifar and Moreno-Equilaz [22].

The paper structure is as follows. In Section 2, a mathematical model for the BLDC motor is presented. In Section 3, the fault and specific harmonics built in the stator current are modeled. In Section 3, the simulation process of the system through both MATLAB and ADAMS is presented in detail. In Section 4, more information on the CWT method used in this paper as well as the energy criteria extraction as a tool for fault detection is given. In Section 5 , the numerical and graphical representations of the simulation results are given to validate the proposed method. Finally, the paper is concluded in Section 6 .

\section{Problem statement}

A precise modeling of the BLDC motor is required to diagnose a fault that should be as close to the reality of the motor as possible. To this end, MATLAB and ADAMS are simultaneously used in this study for system modeling. Here, ADAMS is employed for modeling the rotor and its static and dynamic imbalances, while MATLAB is utilized for simulating the other parts of the system. In order to clarify how MATLAB and ADAMS work together in this model, it can be stated that in Matlab environment, the subtraction of the load torque from the electromagnetic torque is incorporated as an input to the ADAMS rotor model. Then, the rotor (ADAMS) sends out the mechanical angle $\varphi_{m}$, angular velocity $\omega$, and motor imbalances (flywheel disturbance torque). In MATLAB, the stator phase current signal is drawn out of the system to apply CWT. Then, WC signals are obtained via CWT that embody exact information about the current signal at some desired frequency bands. Once the nature of the fault (SITF) is known, it is possible to determine the fault frequencies. Consequently, WCs can be calculated based on those fault frequencies to monitor the current signal for SITF. Finally, the energies of the WCs in a specific time span are calculated and used further to set a threshold for fault detection. This strategy is expected to detect the SITF in all faulty scenarios with different load conditions.

\section{BLDC motor model}

To improve the accuracy of the simulations and determine the faults, a proper motor model should be designed. In other words, the more precise the model is, the more real and exact the results will be. The phase-to-phase voltages of the brushless electric motor are given by $[27,28]$ :

$$
\begin{aligned}
& v_{a b}=R\left(I_{a}-I_{b}\right)+L \frac{d}{d t}\left(I_{a}-I_{b}\right)+e_{a}-e_{b}, \\
& v_{b c}=R\left(I_{b}-I_{c}\right)+L \frac{d}{d t}\left(I_{b}-I_{c}\right)+e_{b}-e_{c}, \\
& v_{a c}=R\left(I_{a}-I_{c}\right)+L \frac{d}{d t}\left(I_{a}-I_{c}\right)+e_{a}-e_{c},
\end{aligned}
$$

where $L$ is the difference between the self and mutual inductances of stator winding; $R$ is the resistance; $I_{a}$, $I_{b}$, and $I_{c}$ are the stator currents of phases " $a$ ", " $b$ ", and " $c$ ", respectively; $v_{a b}, v_{b c}, v_{a c}, e_{a}, e_{b}$, and $e_{c}$ are phase-to-phase voltages and recursive Electro-Motive Forces (EMF) of each phase, respectively.

On the contrary, the relation between the mechanical and electrical positions $\left(\varphi_{m}\right.$ and $\left.\varphi_{e}\right)$ of the rotor in a BLDC motor with $p$ poles can be written as follows [26]:

$$
\varphi_{e}=\frac{p}{2} \varphi_{m}
$$

As shown below, $\tau_{L}$ (the load torque) is the sum of $\tau_{D B}$ (bearing disturbance torque) and $\tau_{D F}$ (flywheel disturbance torque):

$$
\tau_{L}=\tau_{D B}+\tau_{D F}
$$

where $\tau_{D B}$ is obtained using the following equation: 


$$
\tau_{D B}=\tau_{v i s c o u s e}+\tau_{\text {coulomb }}=C_{v} \omega+C_{c} \operatorname{sign}(\omega),
$$

where $\omega$ is the rotor velocity; $\tau_{\text {viscouse }}$ and $\tau_{\text {coulomb }}$ are the viscous and Coulomb frictions, respectively; $C_{v}$ is the viscous friction coefficient, and $C_{c}$ is the Coulomb friction coefficient. The electromagnetic torque of a BLDC motor is derived as:

$$
\begin{aligned}
\tau_{e}= & T_{c}\left(X\left(\varphi_{e}\right) I_{a}+X\left(\varphi_{e}-\frac{2 \pi}{3}\right) I_{b}\right. \\
& \left.+X\left(\varphi_{e}+\frac{2 \pi}{3}\right) I_{c}\right),
\end{aligned}
$$

where $T_{c}$ is the torque constant, and $X(\theta)$ a trapezoidal function that makes the trapezoidal shape of the flux density and electromagnetic torque. Given that the flux density in brushless electric motors is trapezoidal, back EMF on the stator windings and electric torque are also trapezoidal. In addition, $X(\theta)$ is determined separately at each phase of the brushless electric motor. The back EMF on the stator windings can be obtained based on the following equations:

$$
\begin{aligned}
& e_{a}=K_{e} \omega X\left(\varphi_{e}\right), \\
& e_{b}=K_{e} \omega X\left(\varphi_{e}-\frac{2 \pi}{3}\right), \\
& e_{c}=K_{e} \omega X\left(\varphi_{e}+\frac{2 \pi}{3}\right),
\end{aligned}
$$

where $K_{e}$ is the induction electromotive constant. The result of sorting the dynamic-related relations would be the state-space model of the motor:

$$
\begin{aligned}
\left(\begin{array}{c}
\frac{\mathrm{d} I_{a}}{\mathrm{~d} t} \\
\frac{\mathrm{d} I_{b}}{\mathrm{~d} t} \\
\frac{\mathrm{d} \omega}{\mathrm{d} t} \\
\frac{\mathrm{d} \varphi_{m}}{\mathrm{~d} t}
\end{array}\right)= & \left(\begin{array}{cccc}
-R / L & 0 & 0 & 0 \\
0 & -R / L & 0 & 0 \\
0 & 0 & B / J & 0 \\
0 & 0 & 1 & 0
\end{array}\right)\left(\begin{array}{c}
I_{a} \\
I_{b} \\
\omega \\
\varphi_{m}
\end{array}\right) \\
& +\left(\begin{array}{ccc}
2 /(3 L) & 1 /(3 L) & 0 \\
-1 /(3 L) & 1 /(3 L) & 0 \\
0 & 0 & 1 / J \\
0 & 0 & 0 \\
\tau_{e}-\tau_{L}
\end{array}\right) \\
& \left(\begin{array}{c}
v_{a b}-e_{a b} \\
v_{b c}-e_{b c} \\
\tau_{b}
\end{array}\right)
\end{aligned}
$$

where $J$ is the moment of inertia of the rotor and $B$ is the damping coefficient due to friction; $e_{a b}=e_{a}-e_{b}$ and $e_{b c}=e_{b}-e_{c}$ are phase-to-phase back EMFs of the electrical motor. Finally, the current $I_{c}$ can be measured as:

$$
I_{c}=-\left(I_{a}+I_{b}\right)
$$

Remark 1. Eqs. (6)-(12) are modeled in the Simulink space in MATLAB. At the same time, ADAMS software is used for the simulation of the rotor to model the static and dynamic imbalances based on mass-spring mechanisms. ADAMS outputs the mechanical angle as well as the motor velocity, whose respective values $\varphi_{m}$ and $\omega$ are to be substituted in calculations. Moreover, the two last state equations in Eq. (11) can be removed from the model since they are not used for $\varphi_{e}$ and $\omega$ calculations.

\section{Modeling the fault and fault frequencies}

A stator is a substantial component of an electrical motor. For this reason, it is of high importance to diagnose and locate the stator fault before it inflicts serious damage on the motor function. In this regard, an analysis is suggested where the fault is the most common one, i.e., SITF. Figure 1 shows the SITF where the fault occurred within the coil of phase " $a$ ". As shown, $I_{a}$ is the stator current where as 1 is indicative of the part of the healthy winding and as 2 the shorted windings. A circulating current, modeled here as $I_{f}$, is induced in the shorted coils, leading to inverse air-gap flux density. This flux is effective in the magnetic flux field.

To model SITF, a Simulink model was employed, as given in Figure 2. This figure makes a comparison of both healthy and faulty conditions of one of the three stator phases. In this figure, all of the inductances of the stator phases and their associated resistance are considered identical and equal to $L$ and $R$, respectively. Of note, $e_{c}, e_{b}$, and $e_{a}$ stand for the back EMFs. In addition, $r_{s}$ is the resistance that models the winding turns that have been short-circuited, $e_{f}$ the back EMF

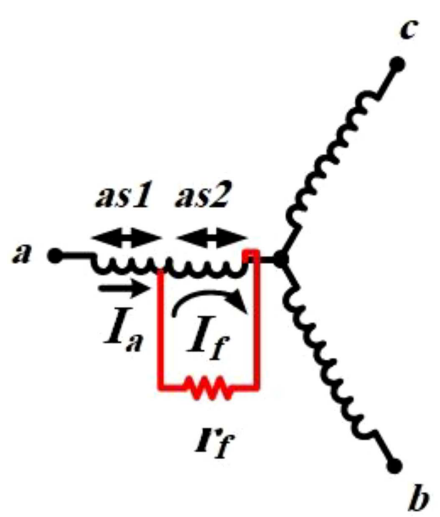

Figure 1. The stator inter-turn fault. 


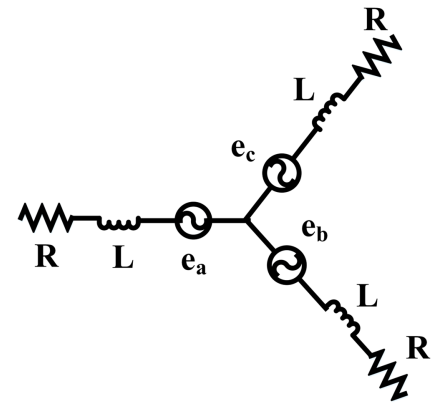

(a)

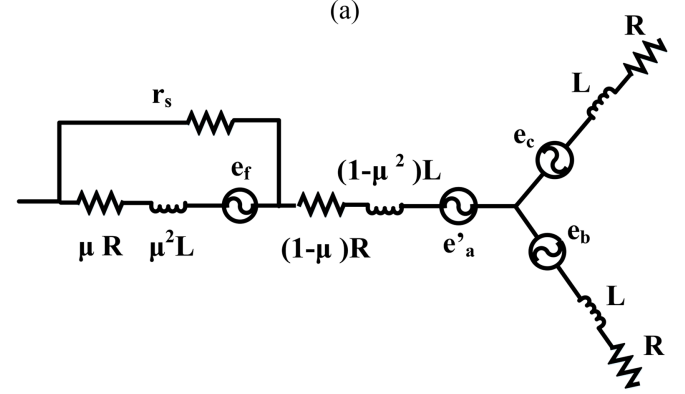

(b)

Figure 2. (a) The healthy three-phase windings of the stator. (b) The faulty three-phase windings of the stator.

derived from short-circuit current, and $\mu$ the rate of short-circuit turns to the whole number of turns at one phase [29]. The fault affects the stator current calculated by Eq. (11). Figure 2(b) shows the modified model of the stator phases accommodating any number of short-circuit turns on one phase. The inter-turn fault is illustrated by a set of elements namely resistance, inductance, and back EMF. There grows a fault current around the short-circuit turns, adding a state variable to the previous mathematical model. Based on the number of short-circuit turns, the fault causes a transition of the phase parameters from normal values. The inductance $L$ should change to $\left(1-\mu^{2}\right) L$ and instead of $R$, we should add $(1-\mu) R$. In the normal operating mode of the motor, the parameter $\mu$ is equal to zero, as shown in Figure 2(a), and the faulty operation mode with non-zero $\mu$ is demonstrated in Figure 2(b). In the case of two or three faulty phases rather than one, the same scenario is repeated for modeling the faulty phase, yet with different amounts for $\mu$ at each phase [19].

With the occurrence of SITF, some harmonics are constructed in the stator current with a pattern described as:

$$
f_{\text {fault }}=(2 n-1) f_{0}
$$

where $f_{0}$ is the fundamental frequency. In this equation, the main (or fundamental) frequency of $f_{0}=20$ $\mathrm{Hz}$ is obtained at a nominal rotor speed of $400 \mathrm{rpm}$. Accordingly, based on the six poles $(P=6)$, the main and side frequencies of failure would be $20,60,100$, and $140 \mathrm{~Hz}$.

\section{The interconnection between MATLAB and ADAMS software}

In this section, the ADAMS software is used to simulate the rotor, which develops a precise model including the static and dynamic imbalances based on mass-spring mechanisms. ADAMS is used as a means to design a model which is beyond theoretical mathematical formulations. This software takes into consideration some uncertainties, which are not included in the formulations. An important difference between a model made in ADAMS and the other made in Simulink is that in the former, some specifications of the rotor such as the physical characteristics are also considered and added. For instance, the rotor is formed as a cylindrical shape with an appropriate cylindrical radius. These features cannot be easily added to the mass-spring model that one can build with Simulink. Furthermore, the entire configuration/form of the rotor can be easily set/edited in ADAMS, making it a suitable candidate for modeling the mechanical subsystem of our system. Figure 3 shows the simulated rotor part in the ADAMS, considering the relevant imbalances. Figure 4 depicts the entire system model including the ADAMS software or rotor and other motor parts already modeled in MATLAB. Accordingly, this figure elaborates how to properly apply Eq. (6) to (12) to the model created in ADAMS. Based on this diagram, first, the commands of $v_{a b}$ and $v_{b c}$ are yielded by the controller and driver sections. Given that the values of these voltages have already been determined, $I_{a}, I_{b}$, and $I_{c}$ currents are acquired based on Eqs. (11) and (12) inside the Stator Block1. In this block, the EMFs $e_{a}, e_{b}$, and $e_{c}$ produced by the Stator Block3 (Eqs. (8) to (10)) are given as the inputs. The stator phase currents, on the contrary, are the inputs for the Stator Block2, in addition to the load torque. Considered as the output of this block, the

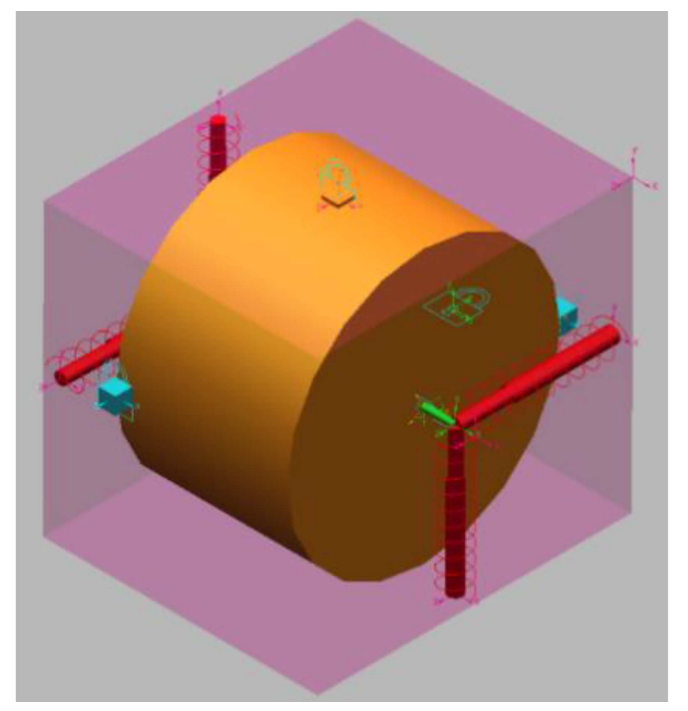

Figure 3. The rotor modeled in the ADAMS software. 


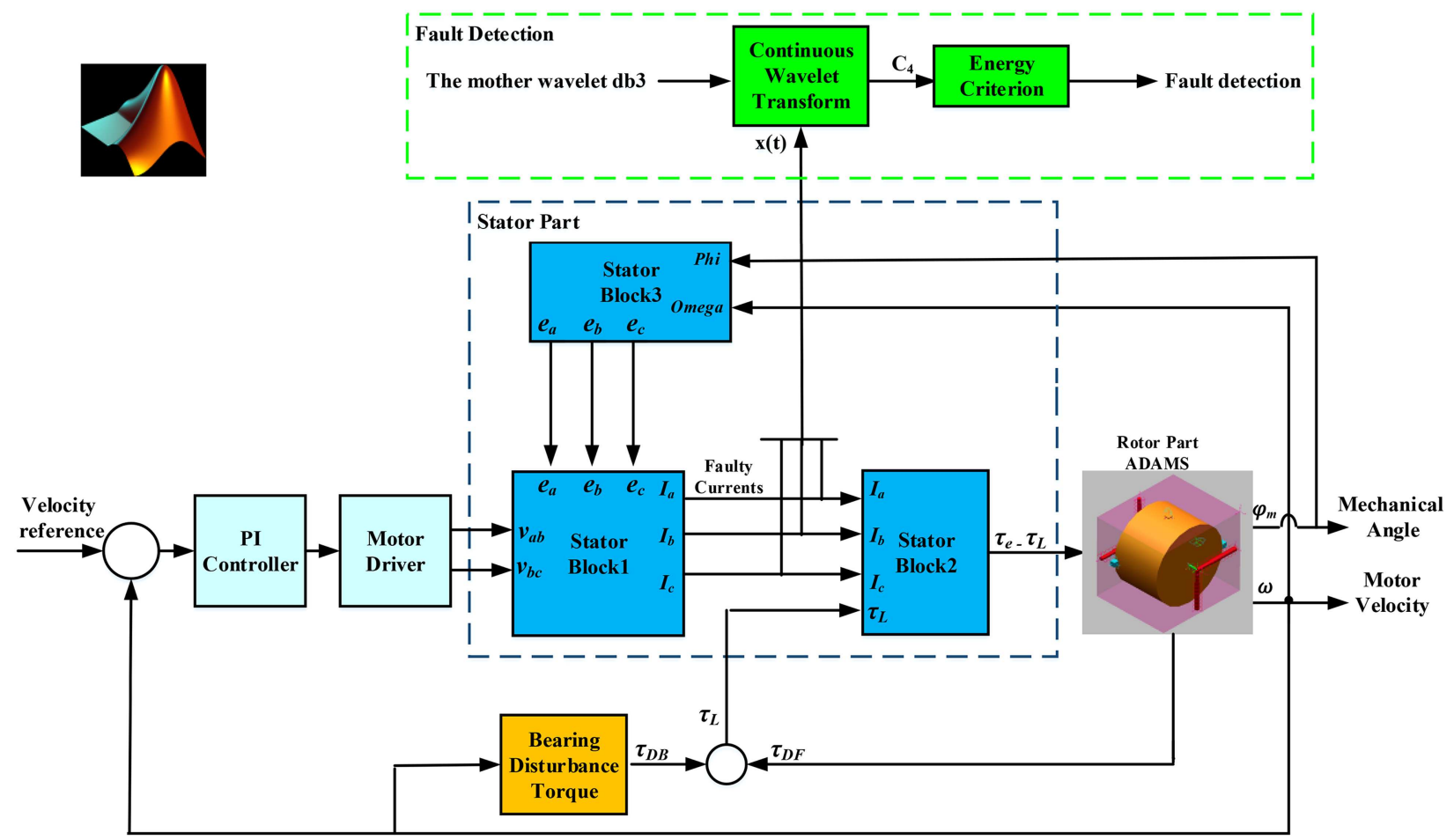

Figure 4. Motor modeling and the interface between MATLAB and ADAMS software.

electromagnetic torque $\tau_{e}$ is derived from Eq. (7) that is sent as an input to the ADAMS block in the rotor after subtracting the load torque $\tau_{L}$ from it [26]. The rotor sends out the mechanical angle $\varphi_{m}$, angular velocity $\omega$, and motor imbalances (flywheel disturbance torque). These signals then return to the respective blocks in the MATLAB software. Eq. (6) is covered in the bearing disturbance torque block outputting $\tau_{D B}$. For fault detection, the stator current of different phases gets faulty characteristics in the Stator Block1, as shown previously in Figure 2(b). Therefore, in this block, different models for healthy and faulty conditions have been implemented. The CWT block then evaluates the output currents explained in the next section of this paper, and the energy calculation process follows the CWT analysis.

The aforementioned series of connections between the stated software are to be used in the simulation subsection to investigate the validity of the designed algorithms.

\section{CWT}

In general, WT is a strong and relatively modern tool with wide applications in signal and image analyses. Wavelet analysis was done by first choosing a proper initial function, idiomatically named "the mother wavelet". Multi-resolution and multi-scale are important features of this analysis approach, indicating that the signal is studied on different scales and resolutions [15]. This paper suggested detecting a fault using CWT, one of the most well-known sub-branches of WT. To be more specific, CWT is defined through the WCs according to the following equation [29]:

$$
W C(s, b)=\frac{1}{\sqrt{|s|}} \int_{-\infty}^{\infty} x(t) \overline{\Psi\left(\frac{t-b}{s}\right)} d t
$$

where the $W C s$ are obtained from the convolution of a signal $x(t)$ with a mother wavelet function $\psi(t)$, which is selected through trial and error, depending a lot on the signal we are examining now. Each WC contains information about the primary signal at a specific frequency band. In this paper, as illustrated in Figure 4, $x(t)$ is the current of the phase "a" of the stator (it could be any of the 3 phases' currents) and it is an input of the CWT block. In addition, $\psi(t)$ function is chosen "db3", one of the functions in a set of particular mother wavelet functions by the name of Daubechies, and it is the second input of the CWT block in Figure 4. Moreover, " $b$ " is the parameter related to the time (or position), while " $s$ " indicates the scale that has an inverse relation with the frequency [30].

$$
F=\frac{F_{c}}{s T_{s}}
$$

where $F$ stands for any frequency of the signal we wish to consider for fault detection, $F_{c}$ the central frequency of the chosen wavelet which is equal to 0.8 $\mathrm{Hz}$ for $\mathrm{db} 3$, and $T_{s}$ the sampling period which was assumed to be $5 \times 10^{-6} \mathrm{~s}$ in this study. 
Table 1. The CWTs relevant to the fault frequencies.

\begin{tabular}{ccc}
\hline $\begin{array}{c}\text { The wavelet } \\
\text { coefficient }\end{array}$ & $\begin{array}{c}\text { The fault } \\
\text { frequency }\end{array}$ & $\begin{array}{c}\text { The scale corresponding } \\
\text { to the fault } \\
\text { frequency }\end{array}$ \\
\hline$C_{1}$ & 140 & 1100 \\
$C_{2}$ & 100 & 1600 \\
$C_{3}$ & 60 & 2500 \\
$C_{4}$ & 40 & 8000 \\
\hline
\end{tabular}

To avoid obtaining excess data, we only derive the WCs concomitant to the SITF specific frequencies. This way, the CWT calculation process would be optimized and efficient. Table 1 identifies the WC signals for each of the fault frequencies already stated in Section 2. Each of the four WCs is related to a specific frequency by the scale parameter shown by $C_{i}, i=1: 4$. The scale that corresponds to each fault frequency is simply acquired through Eq. (15). According to Eq. (14), one can obtain $C_{i}$ signals for a specific period and scale of the system. In this regard, the four obtained WC signals differ in the frequency of the base signal $x(t)$. In other words, each of these WCs evaluates $x(t)$ at one particular frequency of $x(t)$. The time period for which CWT is done should be considered identical among four WCs for abnormality detection at different frequencies.

A glance at Figure 4 reveals that the stator current of one particular faulty phase is to be perused by the CWT block to perform further examinations and determine the defective situation. As the next step toward the detection, the energy of the WCs achieved by the CWT block can be calculated through the relation below:

$$
E_{i}=\frac{1}{N} \sum_{k=1}^{N} C_{i}(k)^{2} ; \quad i=1: 4,
$$

where $E_{i}$ is the calculated energy, $N$ the total number of samples available from each $C_{i}$ signal during the time, and $C_{i}$ the amplitude of this signal at each sample time. As shown in the simulation section later, the obtained value of $E_{i}$ corresponding to specific periods of the base signal (stator current) and different frequencies in that period are the fault detection criteria. These are compared with a consistent threshold proportional to the energy amounts of the healthy operation mode in those specific periods. As a result, $E_{i, \text { healthy }}$ can be obtained. Based on the maximum $E_{i, \text { healthy }}$ in the static state, $E_{\text {threshold }}$ is set with a proper margin. At last, the fault occurrence would be declared whenever the energy amounts rise higher than the threshold $\left(\max \left(E_{i, \text { faulty }}\right)>E_{\text {threshold }}\right)$. It should be noted that it is best to consider $\max \left(E_{i, \text { faulty }}\right)$ among all $E_{i} s, i=1: 4$, which is by far more than the others being significantly affected by the fault. In other words, use of $\max \left(E_{i, \text { faulty }}\right)$ in different periods makes the fault detection process clear and to the point.

Remark 2. The calculation method for energy is superior to the one that uses $C_{i}$ signals directly as a means of detecting abnormality in the stator current in many ways. The SITF occurrence will change the form of $C_{i}$ signals in terms of their amplitude and ripple density. Nevertheless, mere investigation into the shape of a signal is not a proper way to discover the critical situation of a system [18]. Energy calculation yields a numerical value that can be compared with the energy value in other faulty situations resulting from the same or even other similar systems. The amounts of energy determine the severity of the fault. In other words, the higher the energy, the more severe the fault. In addition, a gradual increase in $E_{i}$ can work as an alarm for human operators that prevent the system from complete shutdown or damage of the expensive motor parts. Given that each $C_{i}$ (and hence, each $E_{i}$, according to Eq. (16)) is related to a certain frequency of the base signal (according to Eq. (14)), an energy-frequency criterion and diagram could be achieved through the proposed method. Through this diagram, one can compare the intensity of the fault ripple at every related fault frequency and determine which fault harmonic exists more in the system than the healthy situation.

The next part elaborates on how these energy amounts are used to determine the abnormal faulty situation.

\section{Simulation results}

In this section, the motor model is simulated with its corresponding parameters. Then, the healthy system is examined to obtain the numerical results for this mode of stator action so that this data can be used to detect the faulty condition. In order to find an appropriate threshold for the fault detection criteria, to be further discussed in detail, the healthy system under full-load torque is investigated. This approach will help with not confusing the load torque impact on the system with that of a fault. Then, the fault detection criteria given in this research are introduced based on the observations of the previous simulations. Table 2 includes some numerical information to be used in the related blocks of Figure 4 in MATLAB. Moreover, Table 3 presents the ADAMS software parameters related to our model. Figure 5 refers to the EMF graphs and speed signals.

\subsection{Healthy mode}

To provide a proper perspective of fault occurrence and subsequent fault detection, healthy mode evaluation is a must. The WCs $C_{1}$ to $C_{4}$ (obtained from the stator 
Table 2. The model parameters in MATLAB.

\begin{tabular}{lcc}
\hline \multicolumn{1}{c}{ Parameter } & Value & Symbol \\
\hline Phase resistor & $8 \Omega$ & $R$ \\
Phase inductance & $2 \times 10^{-3} \mathrm{H}$ & $L$ \\
Short-circuit impedance & $9 \times 10^{-3} \Omega$ & $r_{s}$ \\
Moment of inertia & $0.66 \times 10^{-3} \mathrm{~kg} \cdot \mathrm{m}^{2}$ & $J$ \\
Damping coefficient & $2 \times 10^{-5} \mathrm{~N} \cdot \mathrm{m} . \mathrm{s} / \mathrm{rad}$ & $B$ \\
Induction electromotive coefficient & $2 \mathrm{~N} \cdot \mathrm{m} / \mathrm{A}$ & $k_{e}$ \\
Brushless DC motor torque coefficient & $13.689 \times 10^{-3} \mathrm{~N} . \mathrm{m} / \mathrm{A}$ & $K_{T}$ \\
Coulomb friction coefficient & $10^{-4} \mathrm{~N} \cdot \mathrm{m}$ & $C_{c}$ \\
Viscous friction coefficient & $2 \times 10^{-5} \mathrm{~N} \cdot \mathrm{m} . \mathrm{s} / \mathrm{rad}$ & $C_{v}$ \\
Sampling time & $5 \times 10^{-6} \mathrm{~s}$ & $T_{s}$ \\
\hline
\end{tabular}

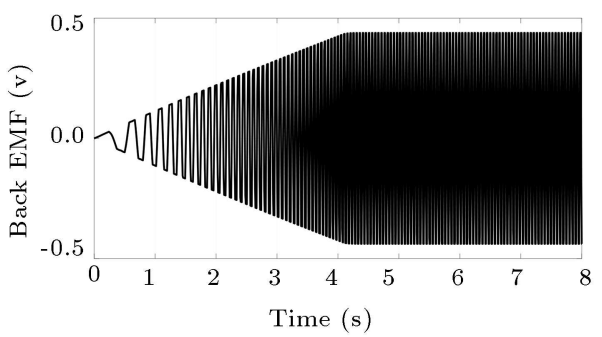

(a)

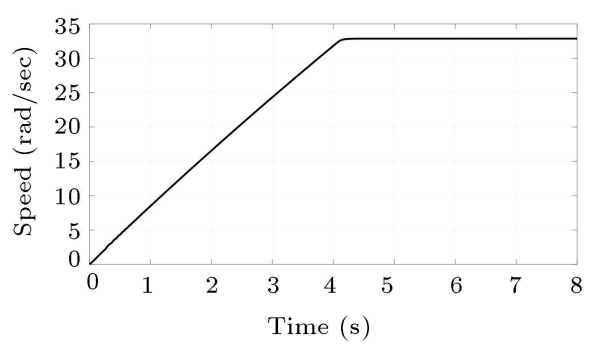

(b)

Figure 5. The output signals of the motor model in the healthy mode: (a) The back EMF signal and (b) the speed signal.
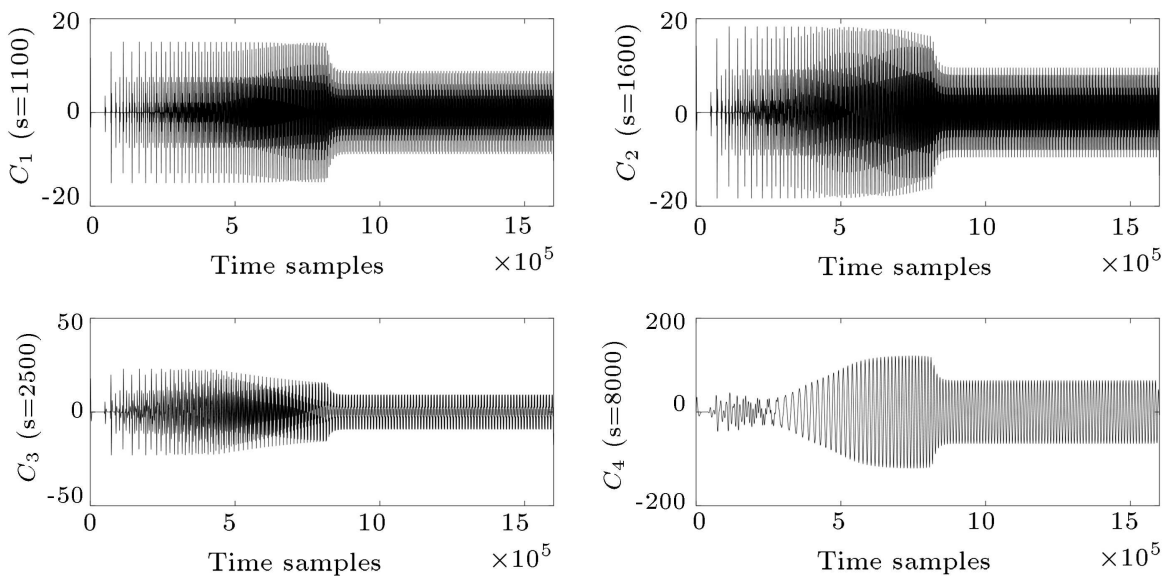

Figure 6. The WCs $C_{1}$ to $C_{4}$ in the healthy mode.

Table 3. The model parameters in the ADAMS simulator.

\begin{tabular}{lcc}
\hline \multicolumn{1}{c}{ Parameter } & Value & Symbol \\
\hline Spring stiffness & $2.1 \times 10^{7}$ & $k$ \\
Spring damper & 5067 & $c$ \\
Cylindrical thickness & $2 \times 10^{-2} \mathrm{~m}$ & $h$ \\
Cylindrical radius & $8 \times 10^{-2} \mathrm{~m}$ & $R$ \\
Dynamic imbalance mass & $3.125 \times 10^{-5} \mathrm{gr}$ & $M_{d}$ \\
Static imbalance mass & $3.75 \times 10^{-6} \mathrm{gr}$ & $M_{s}$ \\
\hline
\end{tabular}

healthy current) are acquired from the MATLABADMAS model and then shown in Figure 6. In this figure, CWT was done on the stator current in the time range of $t=0$ to $t=8$ (at time $8 \mathrm{~s}$, covering both transient and steady states of the system, as shown in Figure 5) and presented as an instance for a figurative view of CWT. The horizontal axis corresponds to the number of samples taken from the stator current for the CWT analysis. It will be shown later that through different periods, $C_{4}$ usually has maximum energy among the four WC signals in Table 1. This characteristic makes $C_{4}$ a better feature than the other WCs to consider singularly as the fault diagnosis criterion. By plotting the time-energy diagram of $E\left(C_{4}\right)$, through 8 seconds of stator action, fault detection is made possible. Figure $7(\mathrm{a})$ and (b) show how $E\left(C_{1}\right)$ to $E\left(C_{4}\right)$ of a healthy signal change in the first eight seconds. According to these figures, $E\left(C_{4}\right)$ fluctuates more significantly than the three other energy amounts. The threshold energy amount for $C_{4}$, considered $E_{\text {threshold }}=5.0000$, which is about 


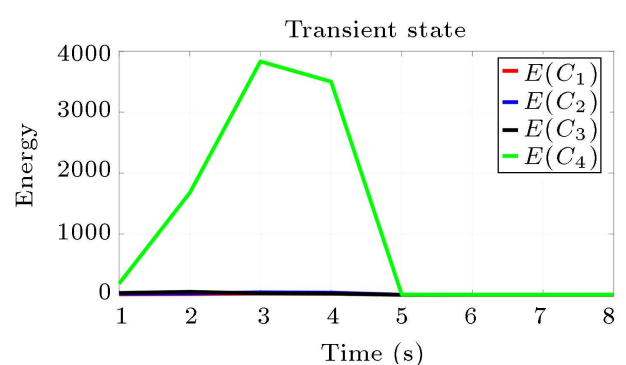

(a)

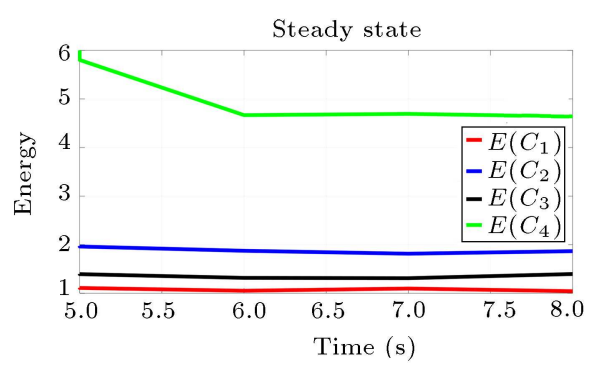

(b)

Figure 7. The time-energy diagram for $C_{1}$ to $C_{4}$ in the healthy mode: (a) Total 8 seconds view and (b) graph zoomed between seconds 5 and 8 to increase precision.

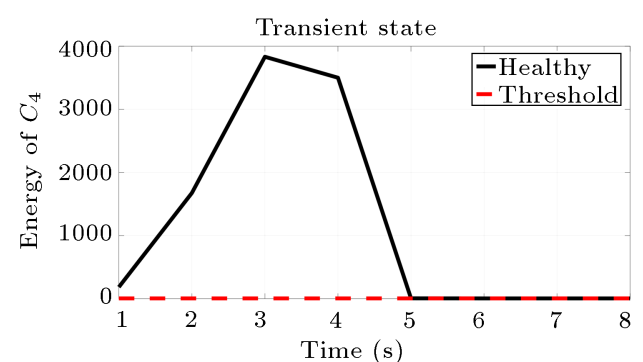

(a)

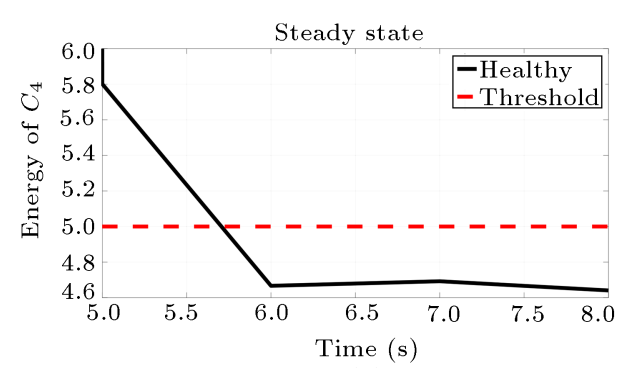

(b)

Figure 8. The time-energy diagram for $C_{4}$ compared to the threshold energy in the healthy mode: (a) Total 8 seconds view and (b) graph zoomed between seconds 5 and 8 to increase precision.

twice $E\left(C_{4}\right)$ of the stator current in the static mode of the healthy full-load system. Note that this margin is for the purpose that small defects and transient conditions do not cause the occurrence of false alarms. Besides, Figure 8 presents a diagram containing the threshold amount at all times and $E\left(C_{4}\right)$. This figure precisely shows how $E\left(C_{4}\right)$ of the healthy signal changes in the first eight seconds compared to the threshold energy amount. The threshold is visible with red color and fixed in the whole observation time period. Table 4 gives the numerical information of the energy amounts of WCs for a healthy operation mode and threshold energy amount. In this table, the duration of time in which each energy amount is calculated is equal to one second. For instance, $T=1$ s refers to the time between seconds 0 and 1 and the specified energy amount is also related to that period.

The next step involves conducting different sim- ulations so that we can validate the proposed fault detection algorithm. To this end, the interconnection created before between the ADAMS and MATLAB software will be used to perform the following scenarios.

\subsection{Fault scenarios}

The current research considers four faulty scenarios described in Table 5:

- Scenario 1: A time-variable fault starting from $t=$ $1 \mathrm{~s}$ and increasing with the initial value of 0 and slope of 0.125 under no load condition;

- Scenario 2: A constant fault with the consistent severity of $\mu=0.25$ starting from $t=4 \mathrm{~s}$ under the load condition of $\tau_{L}=0.01$ N.m.

- Scenario 3: Two involved faulty phases, each with constant faults of the constant severities of $\mu=0.5$ and 0.25 starting from $t=0 \mathrm{~s}$ and $t=5 \mathrm{~s}$,

Table 4. The numerical information concomitant to Figure 7.

\begin{tabular}{cccccc}
\hline \multirow{2}{*}{ Time } & \multicolumn{4}{c}{ Energy } & \begin{tabular}{c} 
The assigned \\
\cline { 2 - 5 } threshold for $\boldsymbol{E}\left(\boldsymbol{C}_{\mathbf{4}}\right)$
\end{tabular} \\
\hline$T=1$ & $\boldsymbol{E}\left(\boldsymbol{C}_{\mathbf{1}}\right)$ & $\boldsymbol{E}\left(\boldsymbol{C}_{\mathbf{2}}\right)$ & $\boldsymbol{E}\left(\boldsymbol{C}_{\boldsymbol{3}}\right)$ & $\boldsymbol{E}\left(\boldsymbol{C}_{\mathbf{4}}\right)$ & 5.0000 \\
$T=2$ & 13.3293 & 18.9310 & 30.9249 & 183.7638 & 5.0000 \\
$T=3$ & 21.0947 & 40.7809 & 23.8932 & 3832.4821 & 5.0000 \\
$T=4$ & 18.1181 & 35.9700 & 20.4967 & 3500.8622 & 5.0000 \\
$T=5$ & 1.1084 & 1.9614 & 1.3931 & 5.8015 & 5.0000 \\
$T=6$ & 1.0509 & 1.8739 & 1.3163 & 4.6667 & 5.0000 \\
$T=7$ & 1.0967 & 1.8139 & 1.3098 & 4.6123 & 5.0000 \\
$T=8$ & 1.0421 & 1.8661 & 1.3956 & 4.6407 & 5.0000 \\
\hline
\end{tabular}


Table 5. The considered fault scenarios.

\begin{tabular}{|c|c|c|c|c|}
\hline \multirow[b]{2}{*}{ Feature } & \multicolumn{4}{|c|}{ Fault scenario number } \\
\hline & 1 & 2 & 3 & 4 \\
\hline Faulty phases & $a$ & $a$ & $a$ and $b$ & $a$ and $b$ \\
\hline Fault type & Time-variable & constant & $\begin{array}{l}\text { a: constant } \\
\text { b: constant }\end{array}$ & $\begin{array}{l}\text { a: constant } \\
\text { b: constant }\end{array}$ \\
\hline$\mu$ & $\begin{array}{l}\text { Increasing with the initial value } \\
\text { of } 0 \text { and the slope of } 0.125\end{array}$ & 0.25 & $\begin{array}{l}\mu_{a}=0.5 \\
\mu_{b}=0.25\end{array}$ & $\begin{array}{l}\mu_{a}=0.5 \\
\mu_{b}=0.25\end{array}$ \\
\hline Fault initiation time & $t=1 \mathrm{~s}$ & $t=4 \mathrm{~s}$ & $\begin{aligned} t_{a} & =0 \mathrm{~s}, \\
t_{b} & =5 \mathrm{~s}\end{aligned}$ & $\begin{aligned} t_{a} & =0 \mathrm{~s} \\
t_{b} & =5 \mathrm{~s}\end{aligned}$ \\
\hline Load torque & 0 N.m. & 0.01 N.m. & 0.01 N.m. & 0.05 N.m. \\
\hline
\end{tabular}

respectively, under the load condition of $\tau_{L}=0.01$ N.m.

- Scenario 4: Two faulty phases involved, each with constant faults having the constant severities of $\mu=$ 0.5 and 0.25 starting from $t=0 \mathrm{~s}$ and $t=5 \mathrm{~s}$, respectively, through the load condition $\tau_{L}=0.05$ N.m (full load).

\subsubsection{Fault Scenario 1}

The proposed algorithm is tested via fault scenario tests for an increasing short-circuit fault in one phase of the stator under a no-load system condition. Figure 9

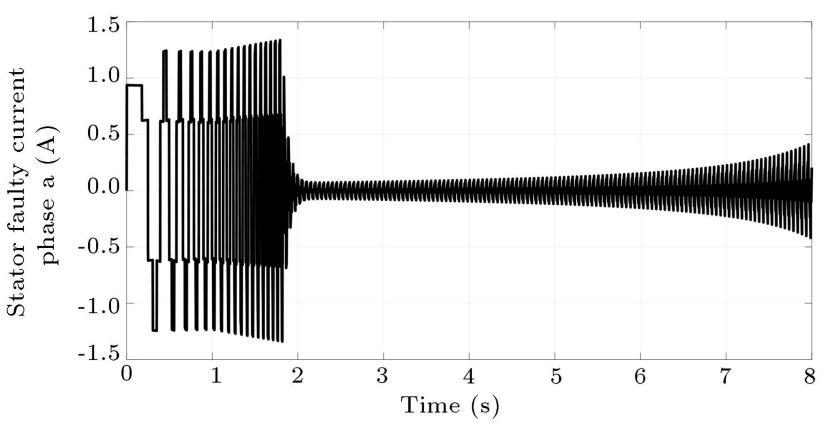

Figure 9. The stator current, in the first 8 seconds of operation, Fault Scenario 1.
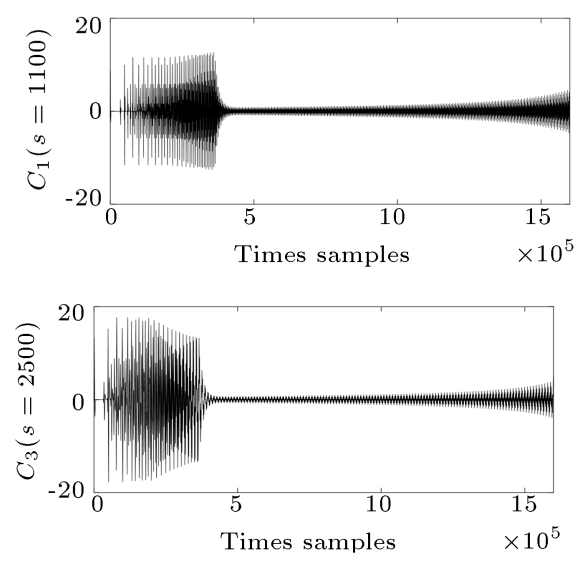

shows the current of the stator within the eight seconds of action. Starting from $t=1 \mathrm{~s}$, while the system is still passing its transient state, the fault makes the current's amplitude constantly rise as the fault grows itself into more and more stator phase winding turns. Figure 10 presents four diagrams of WCs, $C_{1}$ to $C_{4}$, achieved from the stator faulty current at times $t=1 \mathrm{~s}$ to $t=8 \mathrm{~s}$. Diagrams shown in Figure 10 can be compared to those related to the healthy mode illustrated in Figure 6 in terms of their amplitudes to check the gradual fault impact. Figure 11(a) and (b) present a time-energy diagram for $C_{4}$ as well as the threshold value and shows the contrast between them. This diagram proves that $E\left(C_{4}\right)$ grows with time after the fault occurrence. As mentioned earlier, each WC corresponds to the signal frequency based on Eq. (15). As can be seen in Figure 11, it can be interpreted that when a fault emerges $(t=1 \mathrm{~s})$, which is in the transient state up to the moment when steady state begins and $E\left(C_{4}\right)$ passes the threshold ( $t=2 \mathrm{~s}$, based on Figure 9$)$, it takes 1 second for the algorithm to detect the fault. It must be pointed out that $E\left(C_{4}\right)$ needs to be compared to the threshold only after the transient period of the system has passed to make a sound decision about fault occurrence. Hence, it can be stated that the fault
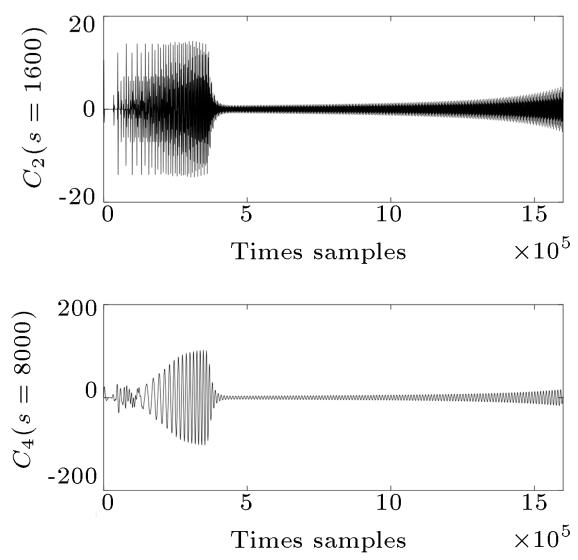

Figure 10. The WCs $C_{1}$ to $C_{4}$, Fault Scenario 1 . 


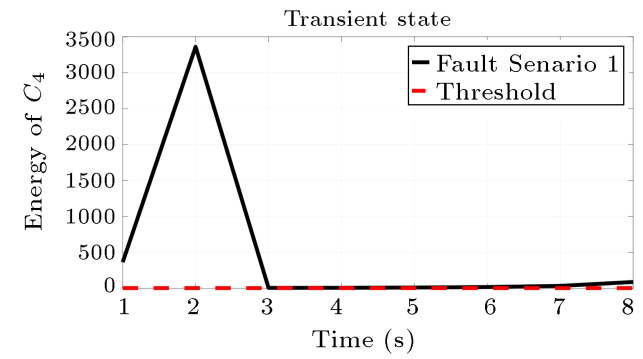

(a)

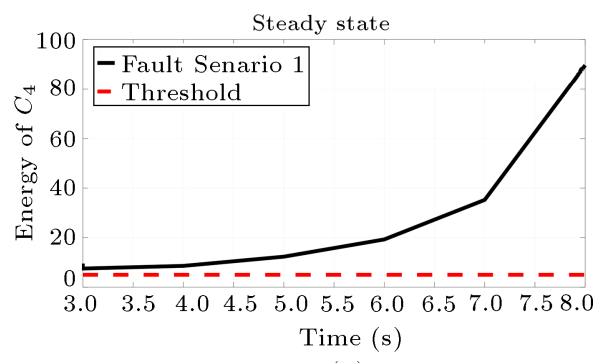

(b)

Figure 11. The time-energy diagram for $C_{4}$, compared to threshold energy, in Fault Scenario 1: (a) Total 8 seconds view and (b) graph zoomed between seconds 3 and 8 to increase precision.

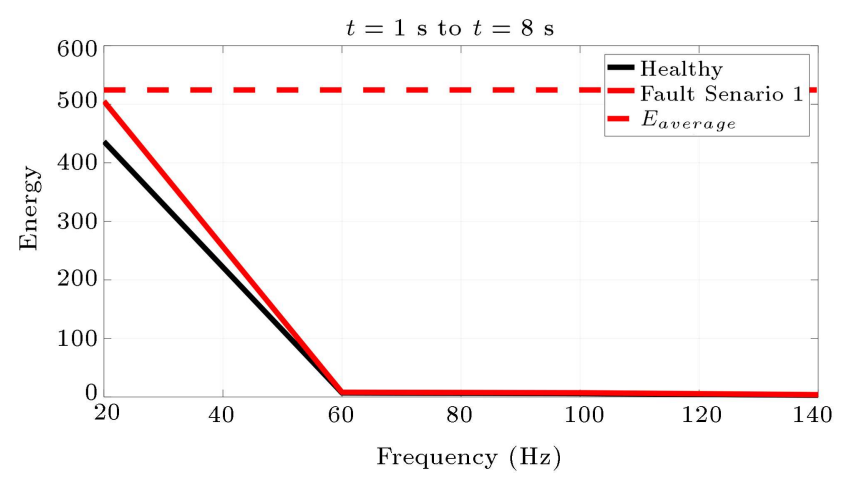

Figure 12. The frequency-energy diagram for $C_{1}$ to $C_{4}$ (at their respective frequencies); $t=1 \mathrm{~s}$ to $t=8 \mathrm{~s}$, in Fault Scenario 1.

detection algorithm makes an immediate decision as soon as the transient mode finishes.

According to Table 1, the four scales are linked to four fault frequencies. Hence, for the faulty stator current, it is possible to create a frequency-energy diagram after the occurrence of the fault $(t=1 \mathrm{~s}$ and, thereafter, the period when the fault initiates and grows). The diagram given in Figure 12 shows a comparison in the energy of the four WCs from four stator current frequencies. The figure constitutes four points along with coordinates $(x, y)$ as follows: $(20 \mathrm{~Hz}$, $\left.E\left(C_{4}\right)\right),\left(60 \mathrm{~Hz}, E\left(C_{3}\right)\right),\left(100 \mathrm{~Hz}, E\left(C_{2}\right)\right)$, and $(140$ $\left.\mathrm{Hz}, E\left(C_{1}\right)\right)$ in the healthy and faulty modes at the prementioned time. In addition, the average value of four $E_{i} \mathrm{~s}\left(E_{\text {average }}\right)$ is calculated and shown in the diagram on a dotted line as a better tool to make a comparison between the healthy and faulty modes. The increase in faulty-mode $E_{\text {average }}$ of these WCs in comparison with $E_{i} \mathrm{~s}$ in the healthy mode is evident in Figure 12.

\subsubsection{Fault Scenario 2}

This scenario deals with the occurrence of a fault in a BLDC motor under 0.01 N.m. load torque. As Figure 13 represents, it seems that the transient time of the stator current has extended over time and the fault has had a greater impact on the stator than that under the no-load condition. As can be seen in Figure 13, the WCs diagrams are presented in Figure 14. Figure 15

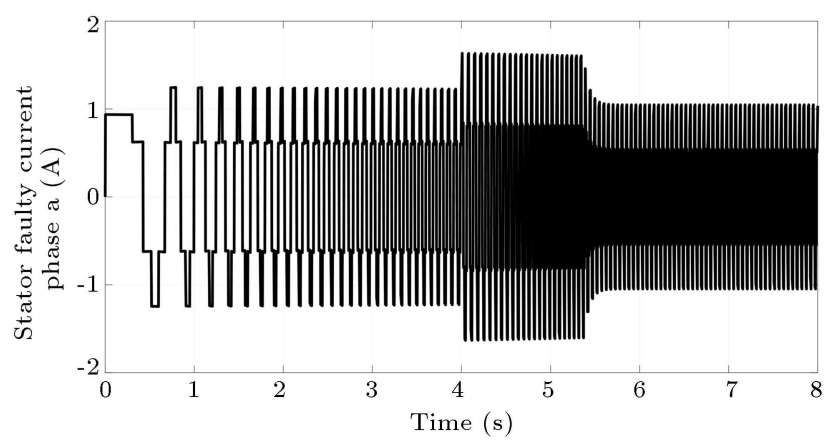

Figure 13. The stator current in the first 8 seconds of initiation, in Fault Scenario 2.

shows $E\left(C_{4}\right)$ time variations in the first 8 seconds compared with the threshold energy amount. The frequency-energy diagrams in Figure 16 facilitate a better understanding of the great impact of the fault on the stator current, specifically on the energy of one of the signal frequencies related to $C_{4}$.

Figure 15 shows that from the moment when fault begins $(t=4 \mathrm{~s})$ to the emergence of the steady state where $E\left(C_{4}\right)$ passes the threshold $(t=5.55 \mathrm{~s})$, it takes 1.55 seconds for the algorithm to detect the fault. The steady state can be tracked by observing the phase current in Figure 13.

\subsubsection{Fault Scenario 3}

This scenario involves fault occurrence at two stator phases (a and b), each having constant severity of $\mu=0.5$ and 0.25 , starting from $t=0 \mathrm{~s}$ and $t=$ $4 \mathrm{~s}$, respectively. The system load torque is equal to 0.01 N.m. The fault detection calculation results are shown for only the phase "a" current signal compared to the previous scenarios. The current signals of two faulty phases are displayed in Figure 17. Figure 18 depicts the coefficient signals for the phase "a" current. Figure 19 shows that $E\left(C_{4}\right)$ of the faulty stator phase "a" signal changes in 8 seconds as well as the timeinvariable threshold value. Figure 20 shows the energy of each of the WCs from $t=0 \mathrm{~s}$ to $t=1 \mathrm{~s}$ (phase "a") in this scenario and compares them with those of the healthy operation mode.

Based on Figures 17(a) and 19, one can notice 

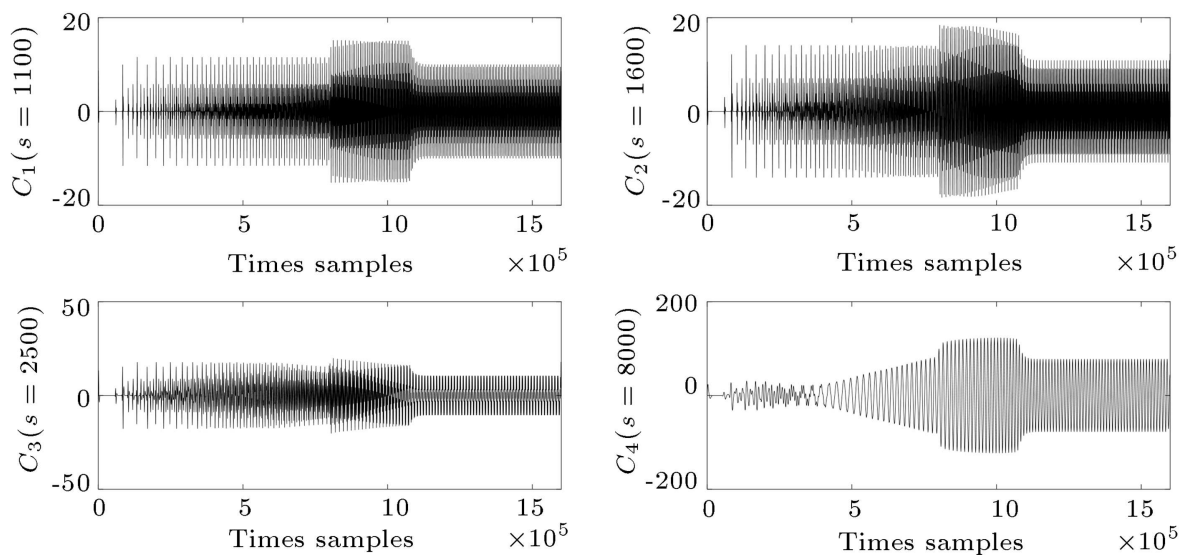

Figure 14. The WCs $C_{1}$ to $C_{4}$ in Fault Scenario 2.

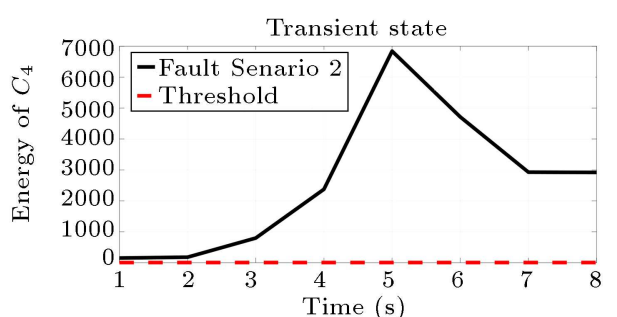

(a)

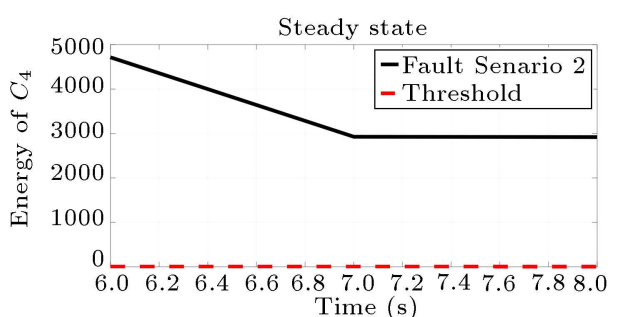

(b)

Figure 15. The time-energy diagram for $C 4$ compared to the threshold energy in Fault Scenario 2: (a) Total 8 seconds view and (b) graph zoomed between seconds 6 and 8 to increase precision.

that from the moment when the fault appears $(t=$ $0 \mathrm{~s})$ until the start of the steady state $(t=7.10 \mathrm{~s})$, it takes 7.10 seconds for the algorithm to detect the fault,

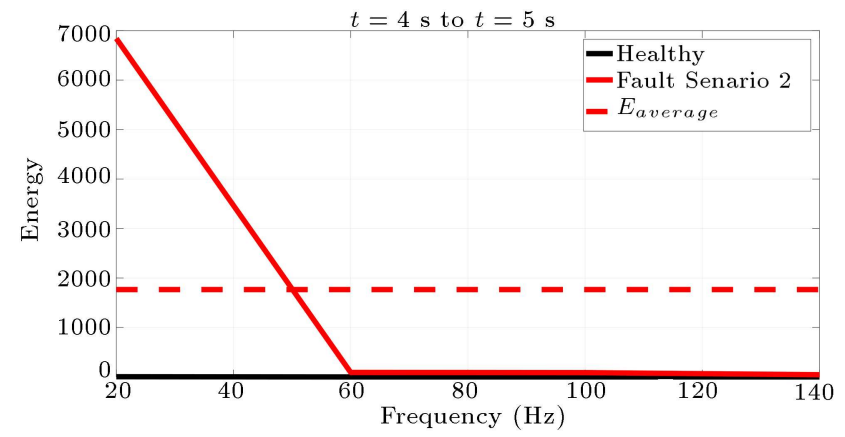

Figure 16. The frequency-energy diagram for $C_{1}$ to $C_{4}$ (in their respective frequencies) in Fault Scenario 2 measured in the period of $t=4 \mathrm{~s}$ to $t=5 \mathrm{~s}$.

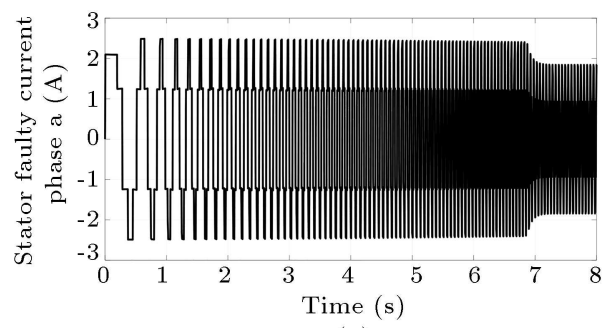

(a) while the difference between the threshold and $E\left(C_{4}\right)$ is relatively high through the passing seconds.

\subsubsection{Fault Scenario 4}

The last scenario studies the full-load system under fault impact. The fault detection algorithm is applied to this system, similar to the previous scenarios. However, for the sake of conciseness, only the $C 4$ timeenergy diagram and the frequency-energy diagram for $C_{1}$ to $C_{4}$, related to the phase "a" stator current, are illustrated in Figures 21 and 22, respectively. It should be noted that the time span for fault detection in this scenario for phase "a" and phase "b" was 8 and 3 seconds, correspondingly. Table 6 presents a summary of the fault scenarios containing $E\left(C_{4}\right)$ at the fault detection moment, fault detection time span, and the load torque. It can be used to compare the cases.

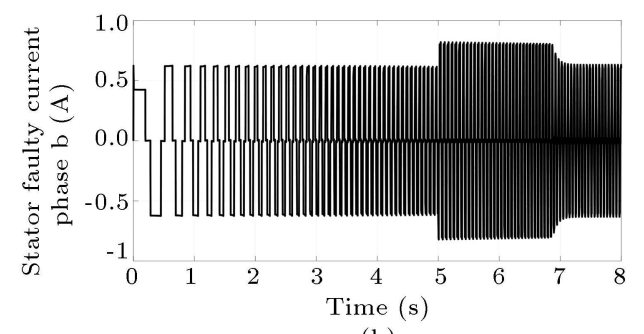

(b)

Figure 17. The stator current in the first 8 seconds of initiation in the fault scenario number 3 of (a) phase "a" and (b) phase "b". 

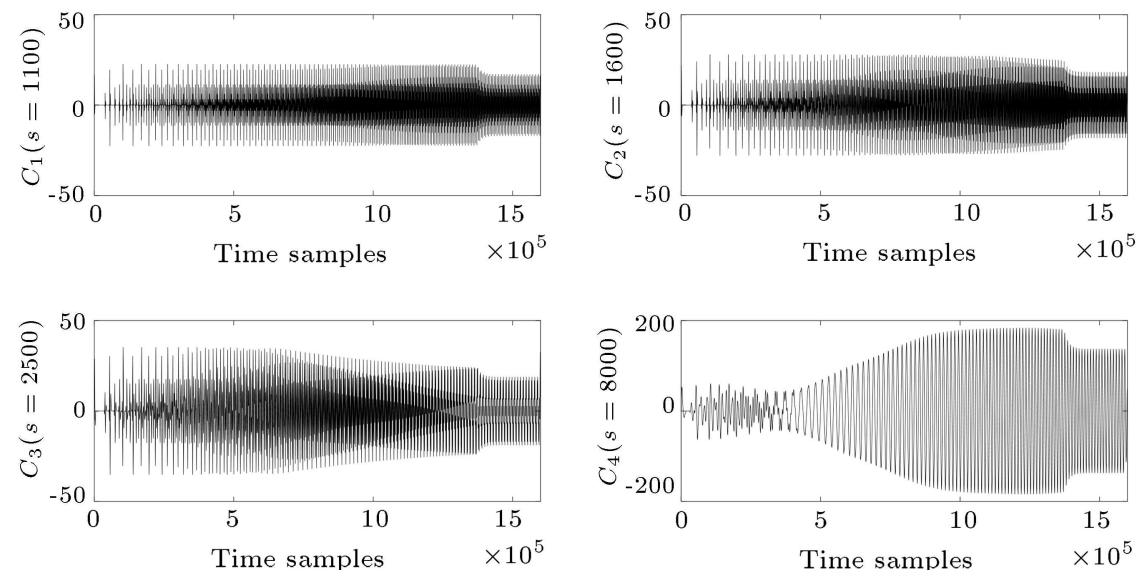

Figure 18. The WCs $C_{1}$ to $C_{4}$ for the phase "a" current in Fault Scenario number 3.

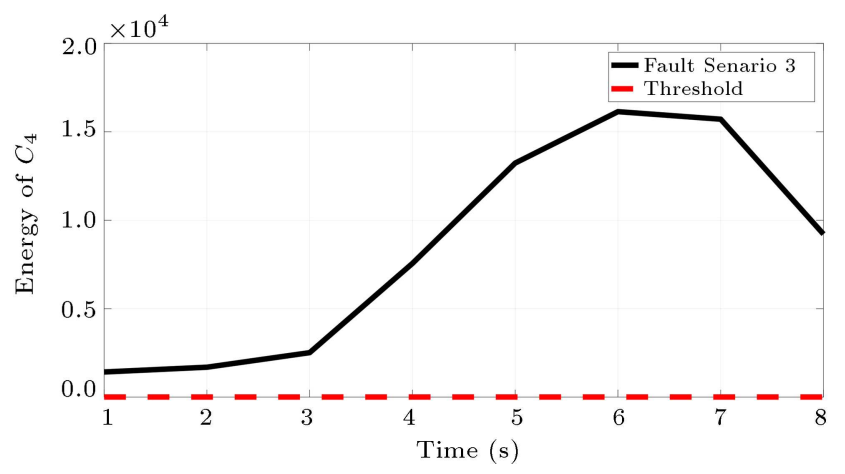

Figure 19. The time-energy diagram for $C_{4}$

(corresponding to the phase "a" stator current) compared to the threshold energy in Fault Scenario 3 from the total 8 seconds view.

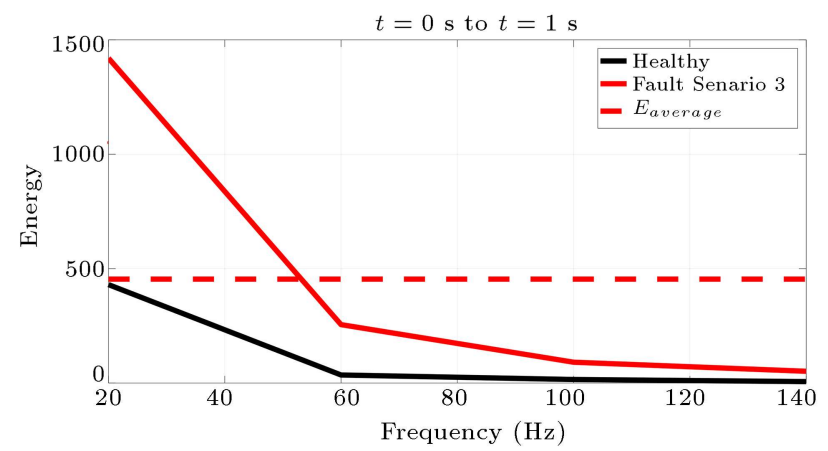

Figure 20. The frequency-energy diagram for $C_{1}$ to $C_{4}$ related to the phase "a" stator current (in their respective frequencies) in Fault Scenario 3 measured in the period of $t=0 \mathrm{~s}$ to $t=1 \mathrm{~s}$.

To sum up, Section 7 investigated four fault scenarios. Scenario 1 was a gradually increasing fault with no load applied to the motor. The fault was applied to the system at $t=1 \mathrm{~s}$ in the transient state. As soon as the current entered its steady state, the detection would be achieved. It takes 1 second for the fault in this scenario to be detected. The second scenario involved a constant fault starting at $t=4 \mathrm{~s}$ in

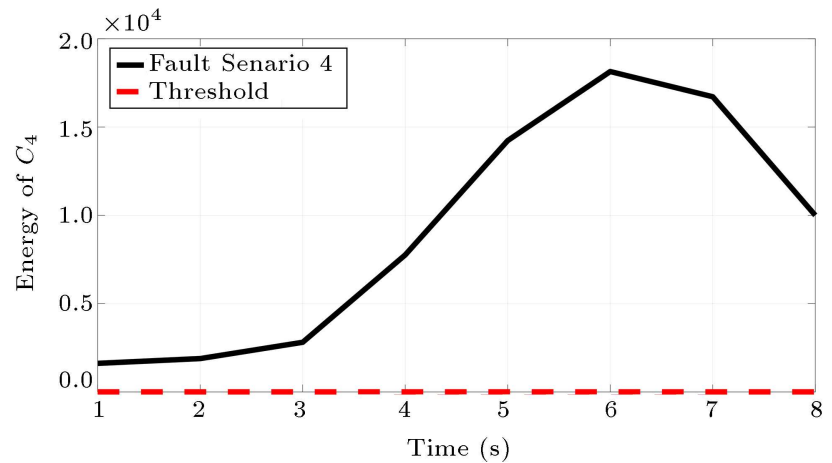

Figure 21. The time-energy diagram for $C_{4}$ (corresponding to the phase "a" stator current) compared to the threshold energy in the fault scenario 4 from the total 8 seconds view.

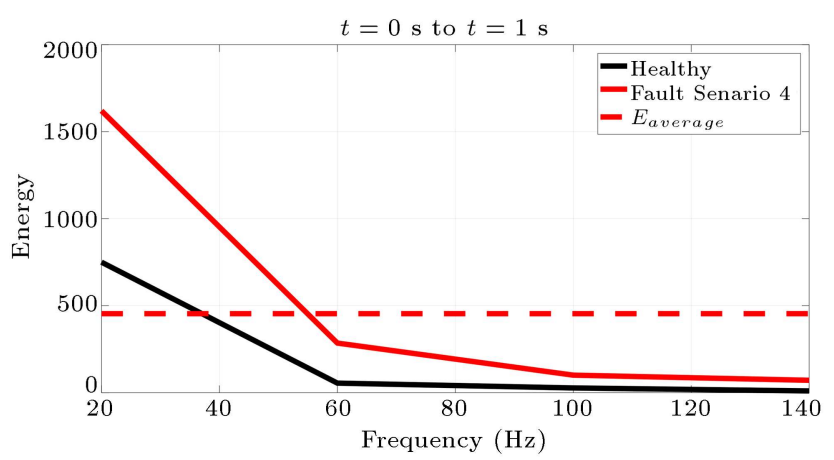

Figure 22. The frequency-energy diagram for $C_{1}$ to $C_{4}$ related to the phase "a" stator current (in their respective frequencies) in the fault scenario 4 measured in the period of $t=0 \mathrm{~s}$ to $t=1 \mathrm{~s}$.

the transient state and there was a load of 0.01 N.m. applied to the system. The fault was detected within $1.55 \mathrm{~s}$. Scenarios 3 and 4 involved the same fault types but occurred in different 0.01 and 0.05 N.m. load conditions. The phase "a" fault was recognized after 7.10 and $8 \mathrm{~s}$, and phase "b" fault was detected after 2.10 and $3 \mathrm{~s}$ in Scenarios 3 and 4, respectively.

The proposed flaw detection algorithm proved to 
Table 6. Summary of all the fault scenarios.

\begin{tabular}{lcccc}
\hline \multirow{2}{*}{ Feature } & \multicolumn{4}{c}{ Fault scenario number } \\
\cline { 2 - 5 } & $\mathbf{1}$ & $\mathbf{2}$ & $\mathbf{3}$ & $\mathbf{4}$ \\
\hline$E\left(C_{4}\right)$ at the fault detection moment & 3359.7905 & 5773.3650 & 15713.8949 & 10000.3206 \\
Load torque & 0 N.m. & 0.01 N.m. & 0.01 N.m. & 0.05 N.m. \\
Fault detection time span & \multirow{2}{*}{$1 \mathrm{~s}$} & \multirow{2}{*}{$1.55 \mathrm{~s}$} & a: $7.10 \mathrm{~s}$, & a: $8 \mathrm{~s}$, \\
& & & b: $2.10 \mathrm{~s}$ & b: $3 \mathrm{~s}$ \\
\hline
\end{tabular}

act effectively in all of the scenarios studied in this paper, as was expected in Section 2. Based on the proposed diagrams and data, one can interpret that the algorithm is used successfully for fault detection. Each of the stator currents acquired from a faulty BLDC motor influenced by our fault scenarios exhibited a different behavior than that in the healthy mode. The energy variation in WCs was compared to the threshold value, which led to fault detection.

\section{Conclusions}

A signal-based analysis approach was investigated in this paper for fault detection purposes. The algorithm was CWT which was applied to the stator current of the BLDC motor model. A part of the research novelty lies in the system model designed in MATLAB and ADAMS software to enhance the model in terms of its precision. In this regard, an energy-based fault detection criterion was proposed. The faulty mode WC signal energy was compared to the predefined energy threshold value. To validate the approach, different fault scenarios were considered. According to the simulation results, it can be stated that the proposed fault detection algorithm is applicable to many conditions such as delayed fault occurrence in the middle of the stator action, a fault already existing in the system from the first phase, a growing fault in one phase, no-load and load conditions, and having two flawed stator phases. The aforementioned process helps any operator to identify the inter-turn fault in the BLDC motor stator phases as early as possible. For further research in this field, it would be possible to achieve experimental results of a real BLDC motor under the short-circuit fault condition. Besides, one can take advantage of more recently developed WTs, which might give more precise fault detection results.

\section{References}

1. Rkhissi-Kammoun, Y., Ghommam, J., Boukhnifer, M., et al. "Two current sensor fault detection and isolation schemes for induction motor drives using algebraic estimation approach", Math. Comput. Simul., 157, pp. 39-62 (2019).

2. Sakunthala, S., Kiranmayi, R., and Mandadi, P.N.
"A study on industrial motor drives: Comparison and applications of PMSM and BLDC motor drives", 2017 Int. Conf. Energy, Commun. Data Anal. Soft Comput. ICECDS 2017, pp. 537-540 (2017).

3. Khan, K.R. and Miah, M.S. "Fault-tolerant BLDC motor-driven pump for fluids with unknown specific gravity: an experimental approach", IEEE Access, 8, pp. 30160-30173 (2020).

4. Patton, R.J., Uppal, F.J., Simani, S., et al. "Robust FDI applied to thruster faults of a satellite system", Control Eng. Pract., 18(9), pp. 1093-1109 (2010).

5. Valdes, A. and Khorasani, K. "A pulsed plasma thruster fault detection and isolation strategy for formation flying of satellites", Appl. Soft Comput. J., 10(3), pp. 746-758 (2010).

6. Aqil, M. and Hur, J. "A direct redundancy approach to fault-tolerant control of BLDC motor with a damaged hall-effect sensor", IEEE Trans. Power Electron., 35(2), pp. 1732-1741 (2020).

7. Roy, S., Alam, M.K., Khan, F., et al. "An irradianceindependent, robust ground-fault detection scheme for PV arrays based on spread spectrum time-domain reflectometry (SSTDR)", IEEE Trans. Power Electron., 33(8), pp. 7046-7057 (2017).

8. Park, J.K. and Hur, J. "Detection of inter-turn and dynamic eccentricity faults using stator current frequency pattern in IPM-type BLDC motors", IEEE Trans. Ind. Electron., 63(3), pp. 1771-1780 (2016).

9. Nayak, N.R., Dash, P.K., and Bisoi, R. "A hybrid time frequency response and fuzzy decision tree for nonstationary signal analysis and pattern recognition", Int. J. Autom. Comput., 16(3), pp. 398-412 (2018).

10. Da Costa, C., Kashiwagi, M., and Mathias, M.H. "Rotor failure detection of induction motors by wavelet transform and Fourier transform in non-stationary condition", Case Stud. Mech. Syst. Signal Process., 1, pp. 15-26 (2015).

11. Moravej, Z., Mortazavi, S.H., and Shahrtash, S.M. "DT-CWT based event feature extraction for high impedance faults detection in distribution system", Int. Trans. Electr. energy Syst., 25(12), pp. 3288-3303 (2014).

12. Abed, W., Sharma, S., Sutton, R., et al. "A robust bearing fault detection and diagnosis technique for brushless DC motors under non-stationary operating conditions", J. Control. Autom. Electr. Syst., 26(3), pp. 241-254 (2015). 
13. Elbouchikhi, E., Amirat, Y., Feld, G., and Benbouzid, M. "Generalized likelihood ratio test based approach for stator-fault detection in a PWM inverter-fed induction motor drive", IEEE Trans. Ind. Electron., 66(8), pp. 6343-6353 (2019).

14. Afrandideh, S., Milasi, M.E., Haghjoo, F., et al. "Turn to turn fault detection, discrimination, and faulty region identification in the stator and rotor windings of synchronous machines based on the rotational magnetic field distortion", IEEE Trans. Energy Convers., 35(1), pp. 292-301 (2020).

15. Hu, R., Wang, J.B., Mills, A., et al. "Current residual based stator inter-turn fault detection in permanent magnet machines", IEEE Trans. Ind. Electron., 68(1), pp. 59-69.

16. Sá, B.A., Barros, C.M.V., Siebra, C.A., et al. "A multilayer perceptron-based approach for stator fault detection in permanent magnet wind generators", 2019 IEEE PES Conf. Innov. Smart Grid Technol. ISGT Lat. Am.,, pp. 1-6 (2019).

17. Shifat, T.A., and Hur, J.W. "An effective stator fault diagnosis framework of BLDC motor based on vibration and current signals", IEEE Access, 8, pp. 106968-106981 (2020).

18. Akhil Vinayak, B., Anjali Anand, K., and Jagadanand, G. "Wavelet-based real-time stator fault detection of inverter-fed induction motor", IET Electr. Power Appl., 14(1), pp. 82-90 (2020).

19. Awadallah, M.A., Morcos, M.M., Gopalakrishnan, S., et al. "Detection of stator short circuits in VSI-Fed brushless DC motors using wavelet transform", IEEE Trans. Energy Convers., 21(1), pp. 1-8 (2006).

20. Zandi, O., and Poshtan, J. "Brushless DC motor bearing fault detection using hall effect sensors and a two stage wavelet transform", 26th Iran. Conf. Electr. Eng. ICEE, pp. 827-833 (2018).

21. Frosini, L., Zanazzo, S., and Albini, A. "A waveletbased technique to detect stator faults in inverter-fed induction motors", Proc. - 2016 22nd Int. Conf. Electr. Mach. ICEM 2016, pp. 2917-2923 (2016).

22. Salehifar, M., and Moreno-Equilaz, M. "Fault diagnosis and fault-tolerant finite control set-model predictive control of a multiphase voltage-source inverter supplying BLDC motor", ISA Trans., 60, pp. 143-155 (2016).

23. Irimia, N.D., Lazar, F.I., and Luchian, M. "Highly redundant actuation system concept with dual stator six phases BLDC motor suitable for automotive industry applications: fault tolerant system actuation design", 2018 Int. Conf. Expo. Electr. Power Eng., pp. 785-790 (2018).

24. Skowron, M., Orlowska-kowalska, T., Wolkiewicz, M., et al. "Convolutional neural network-based stator current data-driven incipient stator fault diagnosis of inverter-fed induction motor", Energies, 13(6), 1475, pp. 1-21 (2020). (2020).

25. Maraaba, L.S., Al-Hamouz, Z.M., Milhem, A.S., et al. "Neural network-based diagnostic tool for detecting stator inter-turn faults in line start permanent magnet synchronous motors", IEEE Access, 7, pp. 8901489025 (2019).

26. Rao, A.P.C., Obulesh, Y.P., and Babu, C.S. "Mathematical modeling of bldc motor with closed loop speed control using pid controller under various loading conditions", ARPN J. Eng. Appl. Sci., 7(10), pp. 1321-1328 (2012).

27. Cheema, M.A.M., Fletcher, J.E., Xiao, D., et al. "A linear quadratic regulator-based optimal direct thrust force control of linear permanent-magnet synchronous motor", IEEE Trans. Ind. Electron., 63(5), pp. 27222733 (2016).

28. Hanselman, D., Brushless Permanent Magnet Motor Design, 2nd edition, Magna Physics Publishing, Motorsoft Division of Fisher Electric Technology, 3000 M Henkle Drive, Lebanon, Ohio 45036, Ohio (2006).

29. Du, B., Wu, S., Han, S., et al. "Interturn fault diagnosis strategy for interior permanent-magnet synchronous motor of electric vehicles based on digital signal processor", IEEE Trans. Ind. Electron., 63(3), pp. 1694-1706 (2016).

30. Saghafinia, A., Kahourzade, S., Mahmoudi, A., et al. "On line trained fuzzy logic and adaptive continuous wavelet transform based high precision fault detection of IM with broken rotor bars", Conf. Rec.-IAS Annu. Meet., IEEE Ind. Appl. Soc., pp. 1-8 (2012).

\section{Biographies}

Saba M. Hosseini holds an MSc degree from Imam Khomeini International University, Qazvin, Iran in 2020 and a BSc degree from Shahid Beheshti University, Tehran, Iran in 2018, both in Electrical Control Engineering. She is a newly admitted $\mathrm{PhD}$ student at the University of Central Florida, Orlando, FL, United States. Her research interests include robotics, control systems, fault detection, and wearable assistive devices.

Mostafa Abedi received the MSc degree from Iran University of Science and Technology, Tehran, Iran in 2007 and the PhD degree from Iran University of Science and Technology, Tehran, Iran in 2014, all in Control Engineering. He is currently an Assistant Professor at Shahid Beheshti University. His research interests lie in the areas of robotics, fault-tolerant systems, and identification and estimation. 